\title{
Competitividade e barreiras não tarifárias nas exportações brasileiras de calçados
}

\author{
Ana Carolina Nunes Fraga* \\ Orlando Monteiro da Silva**
}

\begin{abstract}
Resumo
Este trabalho tem por objetivo identificar a situação do setor calçadista brasileiro no comércio mundial. Foram levantados os dados dos maiores competidores, dos produtos mais exportados e dos principais mercados, e avaliados os índices de vantagem comparativa revelada e as medidas não tarifárias no período 1998-2011. Os resultados mostraram que ocorreu diversificação dos destinos das exportações e uma drástica redução do índice brasileiro de vantagem comparativa, com uma perda substancial de mercado. O calçado de couro natural, principal produto brasileiro do setor, vem perdendo participação no mercado para os calçados de plástico e borracha. Uma avaliação de barreiras tarifárias e não tarifárias indicou que elas não foram o fator decisivo na redução da competitividade. Um desafio importante para o setor é aumentar a produtividade doméstica, reduzir custos e investir em tecnologias que melhorem a qualidade dos produtos.
\end{abstract}

Palavras-chave: Setor calçadista. Vantagem comparativa revelada. Medidas não tarifárias. Notificações técnicas.

* Bacharel em Ciências Econômicas. Universidade Federal de Viçosa. Viçosa, MG. E-mail: anac.nunesf@ gmail.com

*** Professor do Departamento de Economia, PhD. Universidade Federal de Viçosa. Viçosa, MG. E-mail: odasilva@ufv.br

http://dx.doi.org/10.5335/rtee.v21i44.5355

Submissão: 27/06/2014. Aceite: 15/12/2014. 


\section{Introdução}

A produção de calçados no Brasil teve início em 1824 com a chegada de imigrantes alemães ao Sul do país. Eles começaram a produzir artigos em couro, como calçados e arreios de montaria para o Exército, que tiveram grande procura com a Guerra do Paraguai (1864 a 1870). Hoje, a região do Vale dos Sinos, segundo a Abicalçados (2010), é um dos principais polos calçadistas do país e o maior conglomerado desse segmento no mundo. Outra região de grande importância no país é a Região de Franca, no estado de São Paulo, que começou a produzir calçados por volta de 1850, nesse caso em decorrência da chegada de imigrantes italianos, que vieram para o Brasil, inicialmente, visando à expansão da produção de café.

De acordo com Guimarães (2010), foi a invenção da máquina de costura, na década de 1870, que possibilitou o surgimento das primeiras fábricas de calçados. No final do século XIX, os avanços tecnológicos importados da Europa permitiram que a produção de calçados sofresse transição, passando de um processo artesanal para uma atividade fabril. Hoje, o Brasil já é o terceiro maior produtor de calçados do mundo, perdendo apenas para China e Índia.

Anderson (2001) argumenta que no Brasil, até o final da década de 1960, a produção da indústria de calçados era exclusivamente direcionada para o mercado interno e seu dinamismo dependia do crescimento da população e da sua renda per capita. Segundo a autora, a entrada do setor no mercado internacional ocorreu no final dos anos 1960 com a exportação, principalmente, de calçados femininos em couro. Além dos ganhos de escala, a participação da indústria de calçados no mercado internacional gerou ganhos tecnológicos com a modernização e a mecanização da produção e ganhos em qualidade, com um mercado muito mais exigente. Nos anos 1970 e 1980, a produção quintuplicou e somente as vendas para o mercado norte-americano correspondiam a mais de dois terços do total das exportações brasileiras de calçados.

As dificuldades competitivas do setor no mercado externo surgiram com a crise dos anos 1980, quando houve a desaceleração da produção. No início dos anos 1990, o setor continuou se retraindo e a participação no PIB industrial passou de 1,32\%, em 1992, para 0,82\%, em 1995.

Em estudo feito sobre a competitividade brasileira, Costa afirma que:

A competição nesse mercado não ocorre apenas através dos preços, já que o calçado é um produto de moda, com vários modelos e estilos, fabricado com diferentes materiais para atender a múltiplas finalidades de consumo. A diferenciação do produto aparece como outro fator no processo competitivo, e as economias de aprendizado são importantes (COSTA, 1993 apud ANDERSON, 2001, p. 2). 
A indústria de calçados utiliza mão de obra intensiva, pois tem possibilidades limitadas de automação da produção, o que torna essencial a qualificação do trabalhador. A competitividade, portanto, está diretamente ligada a essa qualificação e à tecnologia de produção. Ainda, segundo Costa (1993), maior sofisticação tecnológica é necessária, caso a estratégia seja diferenciar o produto por meio de alterações permanentes no design, enquanto um grau de sofisticação tecnológica menor é suficiente para a fabricação de produtos padronizados a preços baixos.

No comércio internacional, as barreiras tarifárias não são impeditivas, desde que são inexistentes ou de valor muito reduzido. Portanto, são as medidas não tarifárias que devem ser observadas. Essas medidas de proteção não têm aumentado muito nos últimos anos, consequência da redução de tarifas que afetou diretamente as exportações de calçados do Brasil. Um exemplo recente é o da Argentina, que, sem pretextos concretos, atrasa a liberação dos caminhões que transportam os calçados brasileiros para o país. Segundo o artigo de Pietrobelli (2013), para o site Monitor Mercantil, havia 895 mil pares de calçados retidos, o que equivale a um prejuízo de mais de US\$17,7 milhões. O problema com a Argentina é antigo, visto que, de acordo com a coluna de Oliveira (2007), no jornal O Globo on-line, em 2007 já havia divergências entre os dois países quanto aos procedimentos argentinos para a importação de calçados brasileiros.

Torna-se, portanto, importante acompanhar a evolução das exportações brasileiras e de seus competidores nos principais mercados de destino, analisando como as parcelas de mercado mudam e se essas mudanças ocorrem em razão de medidas de proteção não tarifárias.

O objetivo deste estudo, portanto, é avaliar as exportações de calçados do Brasil, identificando a competitividade brasileira em relação aos maiores competidores, para levantar possíveis medidas tarifárias ou não que possam ter contribuído para as mudanças na competitividade nacional. Assim, na seção 2, apresenta-se uma breve descrição do modelo teórico e dos métodos de análise. Na seção 3 , são mostrados e discutidos os resultados, e, na seção 4, encontram-se as principais conclusões deste estudo.

\section{Metodologia}

Desde que Adam Smith começou o estudo da economia internacional em meados do século XVIII, vários outros teóricos, como David Ricardo, Eli Heckescher, Bertil Ohlin e Paul Krugman, aprimoraram as teorias e as adequaram à realidade das transações comerciais internacionais. 
Segundo Krugman e Obstfeld (2010), os países participam do comércio internacional por dois motivos básicos: primeiro, porque eles se beneficiam com suas diferenças, chegando a um arranjo em que cada um produz sua especialidade; segundo, para obter economias de escala na produção, já que cada país produziria algum bem em escala maior e de forma mais eficiente do que se tentasse produzir todos os artigos sozinho. Os padrões do comércio internacional refletem a interação de ambos os motivos, além de objetivos políticos e estratégicos.

Para realmente explicar o comércio entre os países, as teorias pressupõem que ele aconteça sem nenhum entrave ou obstáculo na transação de bens e serviços. No entanto, ao analisar o histórico das trocas comerciais entre as nações, observou-se que o livre comércio jamais existiu de fato, sendo usado apenas para fins acadêmicos, mesmo por seus principais defensores (ANDRADE, 2010).

Há dois tipos de barreiras ao comércio internacional: as tarifárias e as não tarifárias. As primeiras são a forma mais antiga e simples de política comercial, sendo usadas, também, como fontes de receita governamental. Podem ser tarifas específicas, ad valorem, ou mistas, mas, de qualquer forma, têm o efeito de aumentar o preço e reduzir a demanda (KRUGMAN; OBSTFELD, 2010).

Por sua vez, as barreiras não tarifárias são quaisquer medidas e instrumentos de política econômica que afetem o comércio entre dois países e dispensem o uso de mecanismos tarifários. As principais categorias existentes no comércio internacional são: cotas, proibição total ou temporária, salvaguardas, impostos e gravames adicionais (adicionais de tarifas portuárias ou de marinha mercante), impostos e gravames internos que discriminem o produto nacional e o importado (imposto do tipo ICMS que onera o produto importado em nível superior ao do produto nacional), preços mínimos de importação/preços de referência, licenças de importação automáticas (produtos sujeitos a licenciamento em importações apenas para registro de estatísticas), licenças de importação não automáticas (produtos sujeitos à análise prévia de algum órgão do país importador), controles sanitários e fitossanitários nas importações, restrições impostas a determinadas empresas (como exigências específicas para importações de produtos de determinadas empresas), criação de um organismo estatal importador único (produtos cuja importação é feita exclusivamente pelo Estado, em regime de monopólio), requisitos relativos às características do produto, requisitos relativos à embalagem e rotulagem, exigência de conteúdo nacional/regional e de bandeira nacional para o transporte das importações (BERTO, 2004).

É importante salientar que, independentemente da forma, essas barreiras sempre aumentam o preço interno do produto nos países importadores, pois, quando as importações são restritas, a consequência imediata é de que, ao preço inicial, a demanda pelo bem exceda a oferta doméstica mais as importações, fazendo que o preço se eleve. 
As análises da competitividade baseiam-se nos índices de vantagem comparativa revelada e de vantagem comparativa normatizada, observados os maiores parceiros comerciais do país.

O Índice de Vantagem Comparativa Revelada (IVCR) foi criado por Balassa (1965). A ideia principal é de que o comércio exterior de um país "revela" suas vantagens comparativas e de que pela análise das exportações relativas é possível medir a intensidade da especialização do comércio internacional de um país relativamente a uma região ou ao mundo. O IVCR é calculado pela seguinte fórmula:

$$
V C R_{k}=\frac{X_{k} / X_{i}}{X_{K} / X}
$$

Em que $V C R_{k}=$ vantagem comparativa revelada do país $i$ com relação ao produto $k ; X_{K}=$ exportações do produto $k$ pelo país $i ; X_{i}=$ exportações totais do país $i ; X_{k}=$ exportações mundiais totais do produto $k$; e $X=$ exportações totais mundiais.

O IVCR pode variar ao longo do tempo e quando atinge valor maior do que 1 , indica que, naquele período, o país teve vantagem comparativa no produto considerado. Com valores menores do que 1 , há desvantagem comparativa. Um benefício é que o índice VCR pode ser calculado para qualquer nível de desagregação. Contudo, por assumir qualquer valor acima de 1, no caso de vantagem comparativa, e somente com valores no intervalo de zero a 1 para a desvantagem comparativa, ele é um índice assimétrico, o que dificulta a análise dos resultados. Para resolver esse problema, faz-se uma normatização do índice, da seguinte forma:

$$
V C R N=\frac{V C R_{k}-1}{V C R_{k}+1}
$$

A interpretação do índice é semelhante ao anterior, e o diferencial fica por conta da amplitude de variação dos valores, que agora é apenas de $-1 \mathrm{a}+1$. Valores menores que zero indicam desvantagem comparativa, enquanto valores positivos revelam vantagem.

Todos os dados utilizados neste trabalho foram obtidos de duas fontes. Para o cálculo dos índices de vantagem comparativa, os dados foram obtidos no World Integrated Trade Solution (2013). Utilizaram-se dados anuais expressos em dólares, no período de 1998 a 2011, dos valores exportados de diversos produtos da indústria calçadista brasileira e dos principais competidores, classificados no nível de seis dígitos do Sistema Harmonizado de Classificação de Mercadorias (HS-6). As barreiras técnicas incidentes sobre as importações dos diferentes produtos do setor 
foram obtidas do TBT Information Management System, da Organização Mundial do Comércio.

\section{Resultados}

A Tabela 1 ilustra os principais países exportadores de calçados em 1998 e em 2011, com as respectivas participações de mercado. Entre os principais exportadores em todo o período estão China, Itália, Espanha, Indonésia, Portugal, Vietnã, Brasil, Alemanha e França. Durante esse período, houve mudanças significativas nas posições da lista, com o Brasil saindo da sétima posição em 1998, quando exportava $3,16 \%$ do total mundial, para a décima terceira em 2011, quando exportou apenas $1,64 \%$. Outros países que perderam mercado foram Itália e Espanha (que teve sua participação reduzida a menos da metade). A China manteve-se como líder e aumentou sua participação de $38,13 \%$ para quase metade do mercado $(47,77 \%)$ em 2011. Outros países que incrementaram sua participação foram o Vietnã, do sexto para o segundo colocado, com 8,5\% das exportações de 2011, e a Alemanha, que subiu três colocações. Além desses, outros países já aparecem entre os dez primeiros colocados, a exemplo da Índia, Bélgica e Romênia.

Tabela 1 - Maiores exportadores de calçados nos anos 1998 e 2011

\begin{tabular}{ll|r|r|r|r|r}
\hline \multicolumn{1}{c|}{ País } & $\begin{array}{r}\text { Exportações } \\
\text { em 1998* }\end{array}$ & $\begin{array}{r}\text { Participação } \\
\text { no mercado }\end{array}$ & \multicolumn{1}{c|}{ País } & \multicolumn{1}{|c}{$\begin{array}{c}\text { Exportações } \\
\text { em 2011* }\end{array}$} & $\begin{array}{r}\text { Participação no } \\
\text { mercado (\%) }\end{array}$ \\
\hline 1 & China & 18.210 .106 & $38,13 \%$ & China & 53.193 .314 & 47,77 \\
2 & Itália & 6.762 .199 & $14,16 \%$ & Vietnã & 9.465 .671 & 8,50 \\
3 & Espanha & 1.976 .109 & $4,14 \%$ & Itália & 9.410 .620 & 8,45 \\
4 & Indonésia & 1.945 .506 & $4,07 \%$ & Indonésia & 4.395 .901 & 3,95 \\
5 & Portugal & 1.723 .586 & $3,61 \%$ & Alemanha & 2.738 .463 & 2,46 \\
6 & Vietnã & 1.569 .592 & $3,29 \%$ & Índia & 2.677 .436 & 2,40 \\
7 & Brasil & 1.510 .181 & $3,16 \%$ & Portugal & 2.362 .318 & 2,12 \\
8 & Alemanha & 1.083 .275 & $2,27 \%$ & Espanha & 2.248 .898 & 2,02 \\
9 & Tailândia & 988.471 & $2,07 \%$ & Bélgica & 2.086 .569 & 1,87 \\
10 & Reino Unido & 754.374 & $1,58 \%$ & Romênia & 2.082 .878 & 1,87 \\
11 & Outros-Ásia & 750.813 & $1,57 \%$ & Holanda & 2.046 .835 & 1,84 \\
12 & França & 735.527 & $1,54 \%$ & França & 1.697 .917 & 1,52 \\
13 Coreia & 729.528 & $1,53 \%$ & Brasil & 1.493 .641 & 1,34 \\
\hline \multicolumn{2}{l|}{ Total } & 47.762 .050 & $100 \%$ & & 111.342 .981 & 100 \\
\hline
\end{tabular}

Fonte: World Bank, 2013.

*Milhões de dólares americanos. 
Essa mudança está de acordo com a ideia de localizar a produção em países ou regiões que ofereçam salários mais baixos e mão de obra abundante, tendo em vista a natureza intensiva em mão de obra e as possibilidades reduzidas de automação.

A Figura 1 ilustra a evolução das exportações brasileiras de calçados. A classificação utilizada aqui foi a de quatro dígitos do Sistema Harmonizado de Classificação de Mercadorias (HS4), correspondente ao ano de 1996. Foram considerados desde calçados prontos (dos mais diversos materiais) até partes de calçados, como cabedal e solado.

Figura 1 - Participação das diferentes categorias de calçados nas exportações - 1998 a 2011

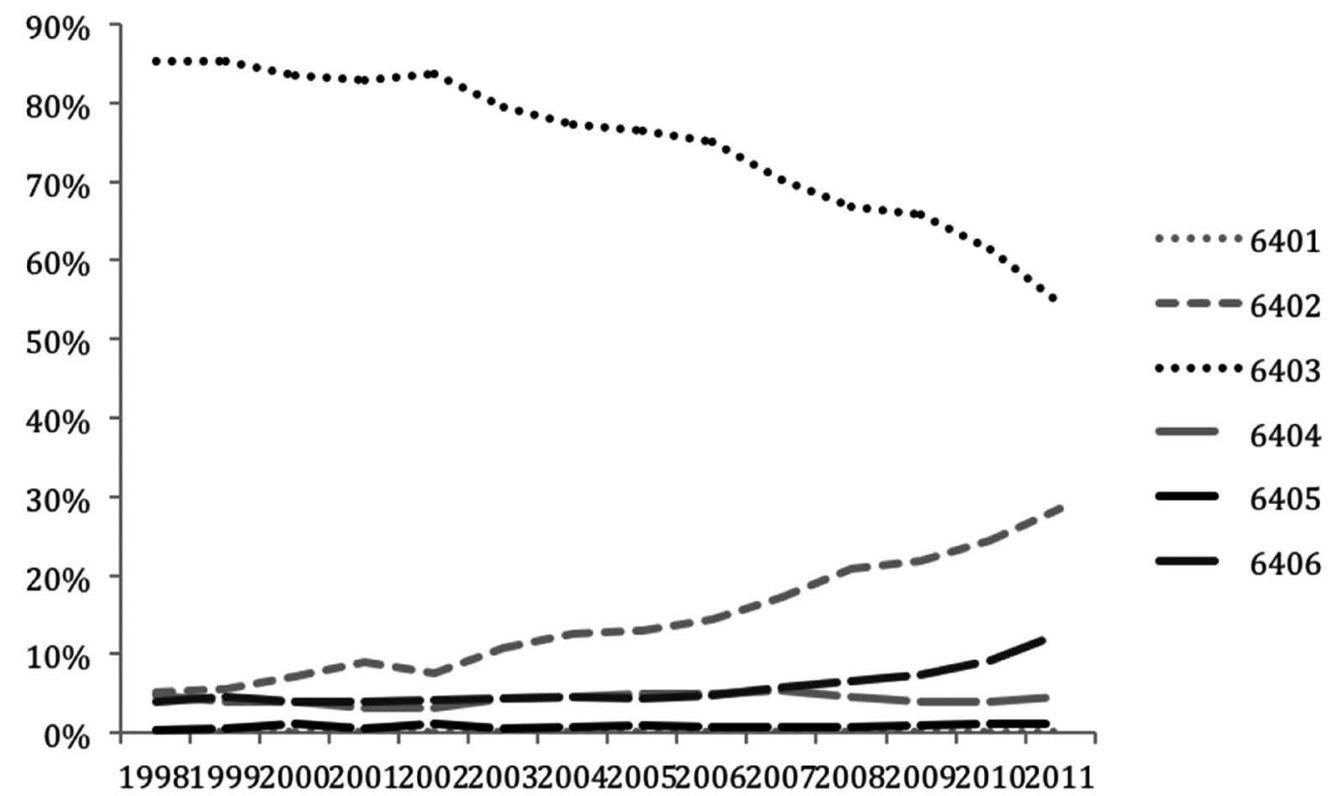

Fonte: elaboração dos autores.

Os dois principais produtos exportados no período analisado foram os das categorias $6.402^{1}$ e $6.403^{2}$. Como pode-se ver na Figura 1, os calçados de couro estão perdendo muito espaço, enquanto que os de plástico ou borracha aumentam sua participação nos mercados externos. Os calçados em couro, que representavam $85,47 \%$ das exportações brasileiras totais desses produtos, chegaram a apenas $54,66 \%$ em 2011. Entretanto, os calçados em plástico e borracha, que correspondiam a somente $5,32 \%$, tiveram sua participação aumentada para $28,61 \%$ do total. 
Outra categoria que teve crescimento significativo foi a de código $6.406^{3}$, referente às partes de calçados que triplicaram a participação, de 3,99\% para $12,75 \%$.

Nas categorias que englobam calçados de borracha ou plástico e suas partes, as economias de escala e a tecnologia são mais significativas e parecem ter contribuído para o crescimento das exportações brasileiras.

Os dez países para os quais o Brasil mais exportou calçados de borracha ou plástico em 1998 foram Argentina, Estados Unidos da América (EUA), Uruguai, Paraguai, Chile, Alemanha, Reino Unido, México, Japão e Peru. Em valores nominais, as exportações aumentaram em todos os países, mas a Argentina, que sozinha era o destino de mais da metade do total exportado, apesar de permanecer como o principal comprador, importou somente $32,68 \%$ do total em 2011 . Outro país que reduziu drasticamente sua demanda pelo calçado brasileiro foram os Estados Unidos, cuja participação foi reduzida a um terço do percentual de 1998. Esses dados são mostrados na Tabela 2.

Tabela 2 - Principais importadores de calçados de borracha ou plástico nos anos 1998 e 2011

\begin{tabular}{ll|r|r|l|r|r}
\hline \multicolumn{1}{c|}{ País } & $\begin{array}{r}\text { Valor Importado } \\
\text { em 1998* }\end{array}$ & \multicolumn{1}{c|}{$\%$} & País & $\begin{array}{c}\text { Valor Importado } \\
\text { em 2011* }\end{array}$ & $\%$ \\
\hline 1 & Argentina & 41.798 & 52,07 & Argentina & 139.112 & 32,68 \\
2 & Estados Unidos & 18.695 & 23,29 & Paraguai & 31.568 & 7,42 \\
3 & Uruguai & 2.330 & 2,90 & Estados Unidos & 26.330 & 6,18 \\
4 & Paraguai & 2.232 & 2,78 & Espanha & 16.819 & 3,95 \\
5 & Chile & 1.691 & 2,11 & Colômbia & 16.514 & 3,88 \\
6 & Alemanha & 1.133 & 1,41 & Austrália & 14.704 & 3,45 \\
7 & Reino Unido & 1.129 & 1,41 & Bolívia & 14.121 & 3,32 \\
8 & México & 1.084 & 1,35 & Peru & 13.631 & 3,20 \\
9 & Japão & 1.075 & 1,34 & França & 12.226 & 2,87 \\
10 & Peru & 1.010 & 1,26 & México & 10.684 & 2,51 \\
\hline Total & 80.268 & 100 & & 425.723 & 100 \\
\hline
\end{tabular}

Fonte: World Bank, 2013.

*Milhões de dólares americanos.

Todos os demais países listados aumentaram suas participações, como as exportações para o Uruguai de calçados de plástico ou borracha dobraram em termos percentuais.

Os dados sobre as exportações de calçados de couro estão apresentados na Tabela 3. Em 1998, os maiores importadores foram EUA, Reino Unido, Canadá, 
Argentina, Chile, Dinamarca, Alemanha, Austrália, França e China. Assim como aconteceu com o mercado dos calçados de plástico e borracha, entre os importadores, o líder (EUA) permaneceu em 2011, porém com uma redução da participação a um terço daquela de 1998. A Dinamarca chama a atenção por ter passado do grupo dos dez maiores importadores para a $57^{\text {a }}$ posição. O país que importava $1,21 \%$ do total em 1998 passou a importar apenas $0,075 \%$, em 2011. O Canadá também não aparece mais entre os maiores importadores e reduziu sua participação pela metade (de $3,34 \%$ para $1,46 \%)$.

Um fato interessante é que, como observado na Tabela 3, mesmo aumentando as participações no total das exportações brasileiras, alguns países perderam posições, como é o caso de Argentina e Chile. Isso indica a melhor distribuição das exportações, tornando o Brasil menos dependente das importações de poucos países, como ocorria em 1998, quando mais de três quartos dos calçados de couro eram exportados somente para os EUA.

Tabela 3 - Principais importadores de calçados de couro nos anos 1998 e 2011

\begin{tabular}{ll|r|r|l|r|c}
\hline \multicolumn{1}{c|}{ País } & $\begin{array}{c}\text { Valor Importado } \\
\text { em 1998* }\end{array}$ & \multicolumn{1}{c|}{$\%$} & \multicolumn{1}{|c|}{ País } & $\begin{array}{r}\text { Valor Importado } \\
\text { em 2011* }\end{array}$ & $\%$ \\
\hline 1 & Estados Unidos & 974.260 & $75,48 \%$ & Estados Unidos & 221.498 & $27,23 \%$ \\
2 & Reino Unido & 108.308 & $8,39 \%$ & Reino Unido & 91.564 & $11,26 \%$ \\
3 & Canadá & 43.103 & $3,34 \%$ & Itália & 61.274 & $7,53 \%$ \\
4 & Argentina & 29.758 & $2,31 \%$ & França & 60.621 & $7,45 \%$ \\
5 & Chile & 16.806 & $1,30 \%$ & Argentina & 32.603 & $4,01 \%$ \\
6 & Dinamarca & 15.576 & $1,21 \%$ & Alemanha & 31.852 & $3,92 \%$ \\
7 & Alemanha & 12.864 & $1,00 \%$ & Chile & 30.427 & $3,74 \%$ \\
8 & Austrália & 11.999 & $0,93 \%$ & Rússia & 26.673 & $3,28 \%$ \\
9 & França & 10.560 & $0,82 \%$ & China & 19.223 & $2,36 \%$ \\
10 China & 9.747 & $0,76 \%$ & Emirados Árabes & 18.146 & $2,23 \%$ \\
\hline Total & 1.290 .789 & $100 \%$ & & 813.477 & $100 \%$ \\
\hline
\end{tabular}

Fonte: World Bank, 2013.

*Milhões de dólares americanos.

Os Índices de Vantagem Comparativa Revelada Normatizada de cada país, em cada ano, estão apresentados na Figura 2. Os valores encontram-se na Tabela A1, do Anexo. Percebe-se que países como Alemanha, França, Bélgica e Holanda apresentam IVC abaixo de zero, indicando desvantagem comparativa, apesar de mostrarem tendência de melhoria ao longo do período. 
Entre os países com vantagem comparativa nas exportações de calçados (valores acima de zero), alguns se mantiveram relativamente estáveis, como Vietnã, Portugal e Itália. Contudo, a maioria apresentou piora nesse índice, como foi o caso de Espanha, Índia, Indonésia, China e Romênia. Inclusive, calçadistas brasileiros que emigraram para a China durante a crise pela qual passou a indústria brasileira na década de 1990, agora sofrem com o aumento dos custos de produção naquele país, principalmente devido ao aumento dos salários chineses, como ressaltado em reportagem recente do jornal Folha de São Paulo (NINIO, 2013).

Infelizmente, nenhum desses países destaca-se tanto quanto o Brasil, que apresentou queda contínua e drástica do IVC a partir do ano 2000, chegando a atingir valor abaixo de zero em 2011 (-0,057), o que denota desvantagem comparativa.

Essa queda na competitividade brasileira tem causas internas e externas. Entre as causas internas, pode-se citar o aumento do Custo Brasil, em que entram os problemas logísticos, devido à falta de infraestrutura básica e à alta carga tributária, além da burocracia e da corrupção. O Custo Brasil também afeta insumos essenciais para a atividade industrial, como energia elétrica, gás natural e internet de banda larga. Contudo, não se pode esquecer um dos insumos mais importantes, que é a mão de obra, cujo custo também tem crescido continuamente no país. Nos últimos anos, ao mesmo tempo em que a taxa de desemprego caminhou para seu piso histórico, os salários cresceram de forma acelerada acima da produtividade do setor, sendo a mão de obra ainda o principal item na estrutura de custos da maioria das empresas brasileiras (SISTEMA FIRJAN, 2013).

Em estudo do Decomtec (2013), ficou comprovado que, até mesmo no mercado interno, um bem manufaturado nacional é, em média, 34,2\% mais caro que um similar importado dos principais parceiros comerciais, já incluindo as alíquotas de importação vigentes, unicamente em razão do Custo Brasil e da valorização do real. Entre as causas externas para a perda de competitividade brasileira estão as barreiras tarifárias e as medidas não tarifárias que, ao elevarem os custos, reduzem as quantidades comercializadas. 
Figura 2 - Evolução do IVCRN dos maiores exportadores de calçados - 1998 a 2011

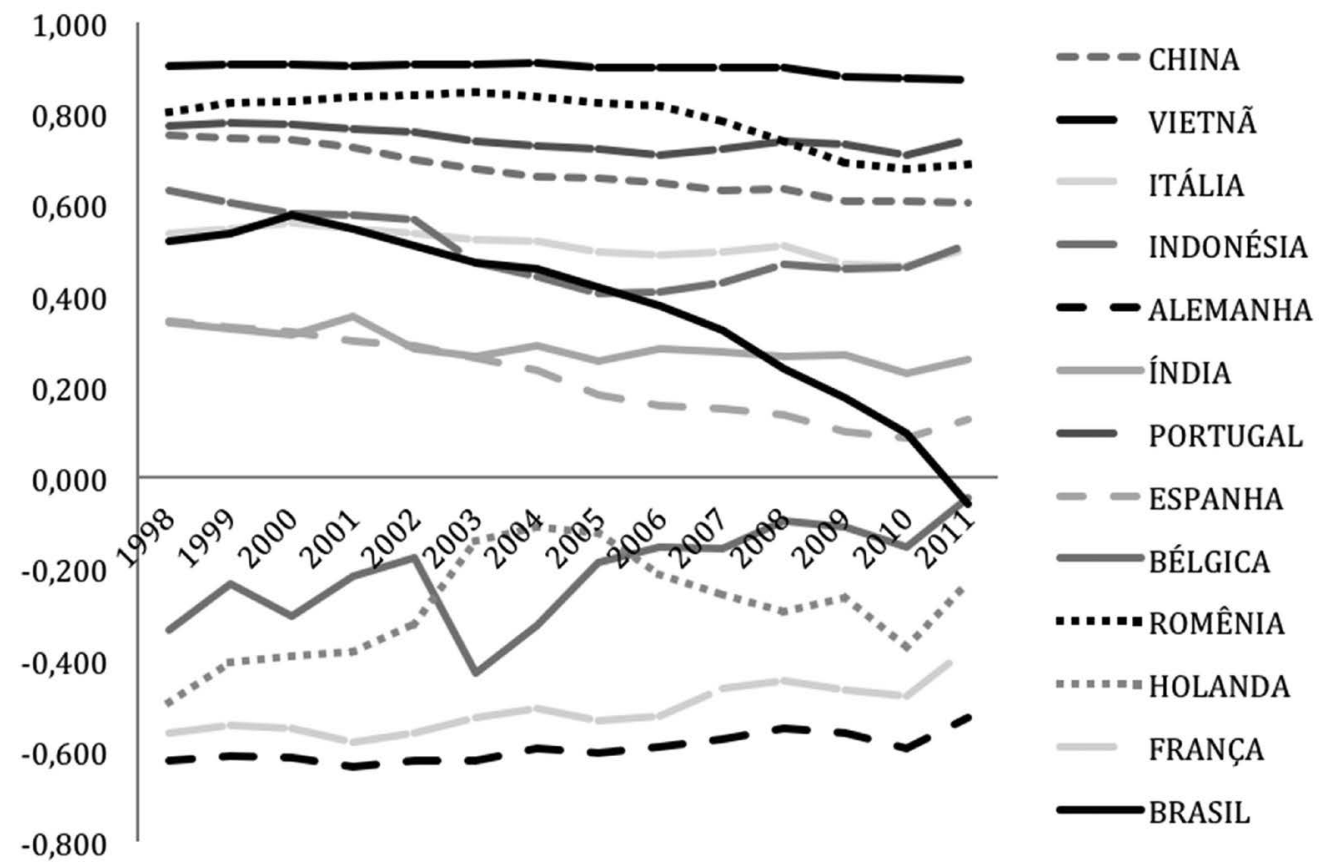

Fonte: elaboração dos autores com dados do World Bank (2013).

No intento de buscar explicação para a perda de competitividade brasileira no setor calçadista, foi feita uma análise das principais tarifas e medidas não tarifárias aplicadas ao principal produto exportado pelo país - os calçados de couro natural com sola exterior - nos destinos em que ocorreram as maiores reduções nas importações. Esses destinos foram: Dinamarca, com redução de 1,21\% para 0,075\%; Canadá, que passou de 3,34\% para 1,46\%; e Estados Unidos, que importavam $75,48 \%$ em 1998 e reduziu para apenas $27,13 \%$ em 2011. Para esses mercados, foram analisadas as medidas tarifárias e não tarifárias que possam ter contribuído para as mudanças apresentadas na competitividade brasileira.

A Dinamarca é um país-membro da União Europeia, em que há livre comércio entre integrantes, mas que impõe uma tarifa externa comum (TEC), aplicável às importações de terceiros países. Além disso, há diferenciação entre os países-membros e não membros da Organização Mundial do Comércio (OMC), com impostos convencionais e os autônomos. Às importações brasileiras são aplicadas, normalmente, as taxas convencionais correspondentes a membros da OMC, salvo quando o produto for beneficiado com direitos preferenciais, estabelecidos no Sistema Geral de Preferências (SGP) comunitário (BRASIL, 2009). 
O SGP foi implementado em 1971 para qualquer produto primário ou industrializado originário de países em desenvolvimento (caso do Brasil), e consiste na eliminação ou redução substancial dos impostos de importação. As concessões de margens tarifárias preferenciais no SGP pelos países desenvolvidos são unilaterais e não recíprocas. Entretanto, a uma vasta gama de produtos brasileiros aplica-se o mecanismo da graduação, que foi definido em 1996 para vigorar a partir de 1999, sob o argumento de que determinados setores produtivos de alguns países seriam suficientemente competitivos para atuarem no mercado comunitário sem precisar dessa vantagem. Assim, os benefícios tarifários foram suspensos quase que completamente desde $1^{\circ}$ de janeiro de 1999.

Entre os produtos brasileiros que sofreram o processo de graduação, encontravam-se artigos em couro e calçados. Dessa maneira, os calçados passaram a ser taxados como qualquer outro produto, passando a pagar o imposto sobre valor agregado (IVA) de $25 \%$, cobrado de mercadorias tanto importadas quanto produzidas localmente. Entretanto, não existem barreiras não tarifárias relevantes aos calçados naquele mercado (BRASIL, 2009).

A Figura 3 mostra o volume importado de calçados de couro brasileiros pela Dinamarca e pelo Canadá, respectivamente, no período entre 1998 e 2011 . No caso da Dinamarca, fica clara a forte queda no valor comercializado a partir de 1999, o que, na falta de barreiras não tarifárias e outros choques que pudessem gerar esse resultado, deve-se ao efeito da graduação pela qual o produto brasileiro passou naquele ano.

Figura 3 - Valor dos calçados de couro brasileiros importados pela Dinamarca e pelo Canadá, em milhões de dólares - 1998 a 2011
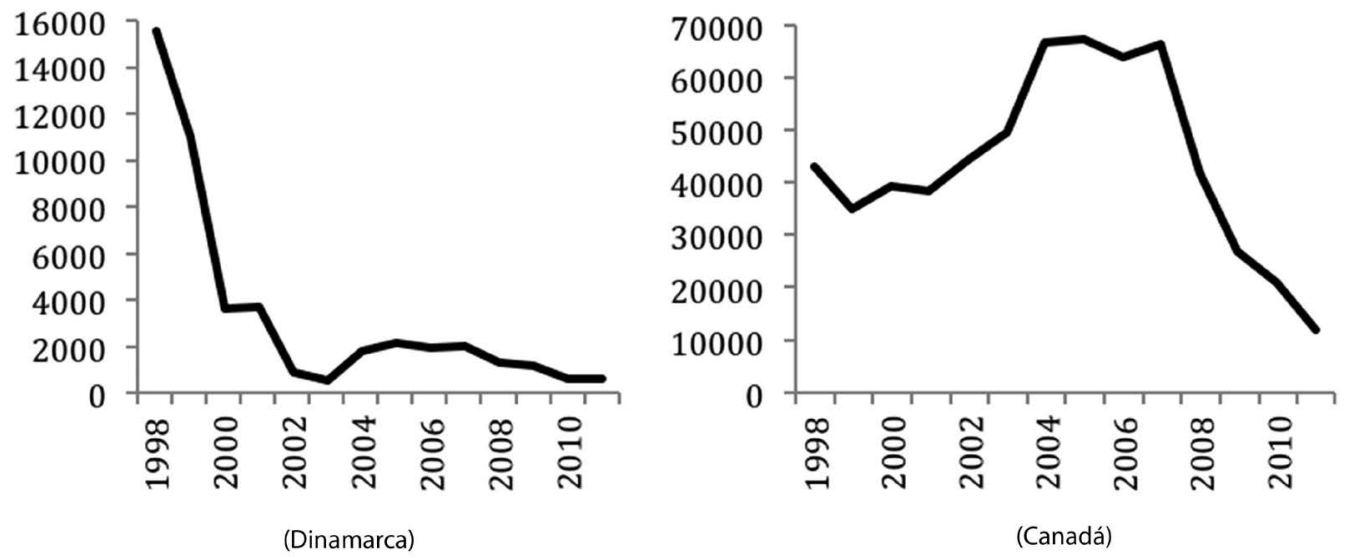

Fonte: World Bank, 2013. 
Segundo o Ministério das Relações Exteriores (BRASIL, 2006), o Canadá cobra, de forma geral, tarifas ad valorem de mais de $15 \%$, inclusive de calçados e artefatos de couro. Contudo, da mesma forma que a Dinamarca, o Canadá adota o Sistema Geral de Preferências, que compreende cerca de 160 países, incluindo o Brasil. Em 2004, a legislação canadense estendeu a validade das tarifas preferenciais aos países beneficiários do SGP por dez anos, ou seja, o acordo passou a vigorar até 30 de junho de 2014. No entanto, a exemplo do país europeu, o governo canadense reserva-se o direito de retirar ou reduzir o benefício tarifário de qualquer produto para um ou todos os países incluídos no sistema, sendo feitas ações de salvaguarda no caso de importações que estejam causando danos aos produtores locais. Dessa forma, assim como fez a Dinamarca, em 2007 o Canadá incluiu os calçados brasileiros no processo de graduação, retirando os benefícios para entrada no mercado local. Inclusive, foi anunciado no dia 9 de outubro de 2013 que, a partir de $1^{\circ}$ de janeiro de 2015 , o Brasil não mais receberá o benefício do SGP daquele país (BARREIRAS COMERCIAIS, 2013).

Pode-se observar na Figura 3 (Canadá) que as importações de calçados de couro brasileiros começaram a declinar justamente com o processo de graduação aplicado pelo Canadá ao produto, o que pode explicar a queda dos anos subsequentes.

No caso dos Estados Unidos, que são responsáveis por 13\% das importações mundiais, apesar da acentuada queda provocada pela crise de 2008 , tanto as importações quanto as exportações começaram a se recuperar ainda no final de 2009 (BRASIL, 2012).

As tarifas dos EUA sobre os calçados de couro são baixas e somente em alguns casos específicos, como no dos calçados de couro para jogar golfe, é que a tarifa chega a $10 \%$ ad valorem (UNITED STATES INTERNATIONAL TRADE COMMISSION, 2014). Da mesma forma que o Canadá e a Dinamarca, os Estados Unidos também fazem uso do Sistema Geral de Preferências, porém, ao contrário deles, não aplicou a graduação aos calçados brasileiros. Como um dos maiores compradores desse tipo de produto, carecendo de importar para suprir a demanda interna, não faria sentido adotar uma medida que aumentasse o preço de um produto de sua necessidade. Quanto às barreiras não tarifárias, os Estados Unidos apresentam regulamentações técnicas apenas em relação a calçados para crianças e calçados de proteção. Ciente disso, não se pode apontar as barreiras não tarifárias como razão para a diminuição das importações de calçados de couro brasileiros, observada na Figura 4 (Estados Unidos). 
Figura 4 - Valor dos calçados de couro brasileiros importados pelos Estados Unidos e pela China, em milhões de dólares - 1998 a 2011

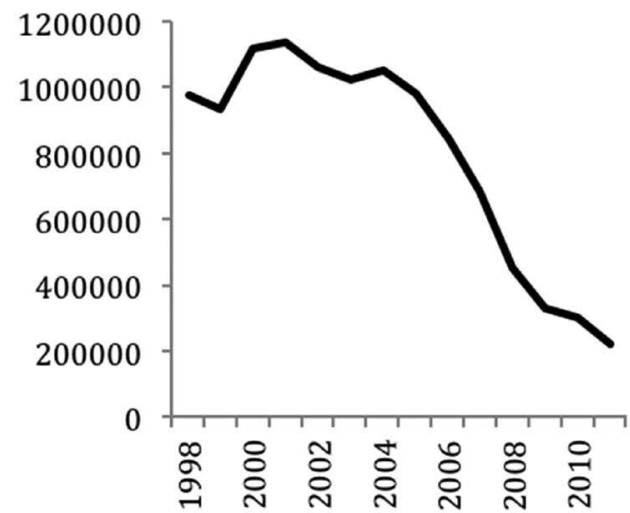

(Estados Unidos)

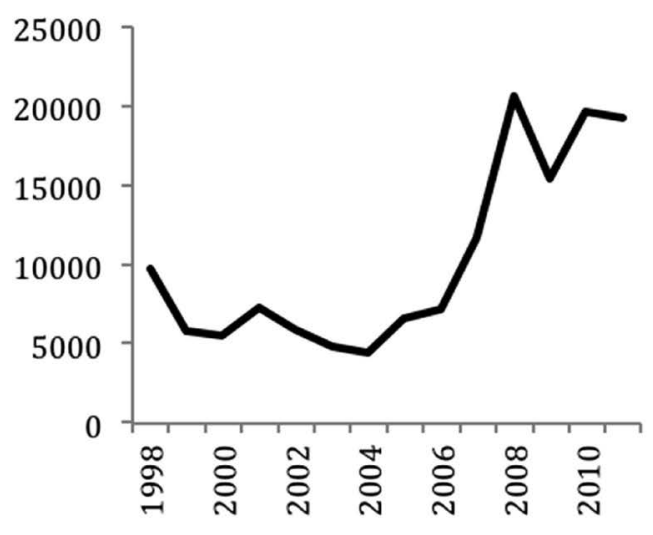

(China)

Fonte: World Bank (2013).

De acordo com o World Trade Organization (2013), entre os dez maiores importadores de calçados de couro brasileiros, apenas a China apresentou duas notificações de normas técnicas para a importação de calçados. Uma das notificações foi emitida em 2005, específica para a categoria 6.403 (calçados de couro), e define o limite de materiais nocivos e as regras de fiscalização, além de incluir normas para a formatação e a redação do documento de notificação. Além do mais, essa notificação abrange qualquer produto de couro usado diariamente, como roupas ou mesmo mobílias, excluindo apenas materiais brutos empregados como insumo na produção chinesa. A outra notificação foi emitida em 2007 e refere-se a todo e qualquer tipo de calçado, definindo regras ainda mais rígidas quanto aos requerimentos técnicos relacionados à saúde e à segurança e a métodos de teste de qualidade e de amostragem. A justificativa adotada foi a preservação da segurança do meio ambiente e da integridade física dos consumidores.

A China é o principal exportador do produto, tendo exportado, em 2011, quase a metade dos calçados comercializados no mundo (47,77\%), de acordo com o World Bank (2013). No entanto, a China tem visto sua vantagem comparativa ser reduzida ao longo dos anos e, por isso, procura proteger seu mercado interno, ao contrário dos Estados Unidos, que é somente importador.

É interessante observar, como apresenta a Figura 4 (China), que as notificações chinesas não resultaram em queda no valor dos calçados de couro brasileiros 
importados. O efeito da segunda notificação (2007) pode ter coincidido com a grave crise econômica internacional, que provocou impactos significativos na produção e no comércio mundial. Não se pode afirmar, portanto, que o declínio da quantidade importada seja explicado pela notificação técnica, mas, sim, pela crise financeira, visto que no ano 2010 o comércio mundial já se recuperava, coincidindo com o novo crescimento das importações chinesas.

\section{Considerações finais}

O fluxo do comércio de calçados no mercado internacional mais do que duplicou entre 1998 e 2011, justificado pelo aumento das exportações dos países asiáticos. A China quase triplicou suas exportações, mantendo a posição de líder e expandindo sua participação no mercado, que atingiu quase 50\% em 2011. A Indonésia e o Vietnã também contribuíram para esse crescimento, dobrando suas vendas e ganhando posições entre os maiores exportadores.

É notório que o Brasil ainda tem importante papel no setor calçadista, mas, de maneira oposta aos países asiáticos, foi um daqueles cujas exportações de calçados mais caíram, com participação nas exportações totais reduzidas de 3,16\% para somente $1,34 \%$. A análise dos índices de vantagem comparativa revelada deixou clara a perda de competitividade de vários países, mas em nenhum deles a queda se comparou àquela do índice brasileiro, que chegou a ser negativo em 2011, indicando desvantagem comparativa.

O principal produto vendido pelo Brasil era o calçado de couro natural com sola exterior de borracha, plástico ou couro, que representava $85,47 \%$ de todos os calçados exportados pelo país em 1998 e que foi perdendo participação, continuamente, até atingir pouco mais da metade das vendas em 2011 (54,66\%). O valor exportado diminuiu não só em termos relativos, mas, também, em valores absolutos.

Uma hipótese era a de que as barreiras não tarifárias pudessem ter sido o fator decisivo para esse cenário. Por isso, foram selecionados os países que apresentaram maior queda das importações do produto brasileiro entre 1998 e 2011 (Dinamarca, Canadá e Estados Unidos), para uma análise mais detalhada.

Tanto na Dinamarca quanto no Canadá, verificou-se que no início do período analisado o Brasil era beneficiado pelo Sistema Geral de Preferências, com eliminação ou redução substancial dos impostos de importação. Porém, em ambos os países os calçados brasileiros passaram pelo processo de graduação e de cobrança de uma tarifa ad valorem sobre os calçados. Nenhum desses países apresentou notificações técnicas ou qualquer outro tipo de entrave à entrada do produto no período 
estudado. Portanto, a causa da diminuição das compras de calçados brasileiros dos dois países foi a mesma: o aumento das tarifas pela redução do benefício do SGP.

Nos Estados Unidos, não foi encontrada nenhuma barreira significativa ao comércio de calçados, o que é totalmente coerente, pois, como país grande importador, não tomou nenhuma medida que aumentasse o preço interno do produto.

Um levantamento das notificações técnicas emitidas pelos maiores parceiros do Brasil, entre os anos 1998 e 2011, apontou que apenas a China emitiu notificações regulando a importação de calçados, mas essas medidas não foram decisivas para diminuição das importações daquele país.

Outro fato importante observado foi a diversificação dos países importadores ao longo dos anos, o que mostra que o Brasil não está dependente das importações de apenas alguns poucos países.

O desafio do Brasil para ganhar competitividade, não só no setor calçadista, é fazer mudanças estruturais em sua economia, investindo em novas tecnologias, infraestrutura e treinamento de mão de obra, de modo a diminuir custos e aumentar a qualidade do seu produto, já que produtos de baixa qualidade, com custos elevados e pouca tecnologia tendem a ser excluídos do mercado. Somente assim o país voltará a ser um dos principais exportadores de calçados do mundo e poderá competir com os demais países. 


\title{
Competitiveness and non tariff barriers in Brazilian footwear exports
}

\begin{abstract}
This study aimed to identify the situation of the Brazilian footwear sector in the world markets. We surveyed the major competitors, the most exported products to the major countries of destination, beside calculate and analyze indices of revealed comparative advantage and non-tariff measures in the period 1998-2011. The results showed that there was diversification of export destinations and a drastic reduction of the Brazilian index of comparative advantage with a substantial market loss. The footwear of leather, which is the main Brazilian product in that sector, has been losing market share to plastic or rubber shoes. An evaluation of tariff and non-tariff barriers has shown that they were not the decisive cause in reducing the Brazilian competitiveness. An important challenge to the sector is to increase its domestic productivity, reduce costs and invest in technologies that improve the quality of products.
\end{abstract}

Keywords: Footwear sector. Comparative advantage. Non trade measures. Technical notifications.

\section{Competitividad y barreras no arancelarias em exportaciones de calzado em Brasil}

\section{Resumen}

Este estudio tuvo por objetivo identificar la situación del sector de calzado de Brasil en el comercio mundial. Los principales competidores y los productos más exportados, los principales mercados fueron encuestados, y se evaluaron los índices de ventaja comparativa revelada y las medidas no arancelarias en el período 1998-2011. Los resultados mostraron que no había diversificación de los destinos de exportación y una drástica reducción del índice brasileño de la ventaja comparativa, con una pérdida sustancial de mercado. El calzado de cuero, un de los principales productos brasileños en la industria, ha ido perdiendo cuota de mercado para el calzado de plástico y caucho. Una evaluación de los aranceles y las barreras no arancelarias, indicó que no fue el factor decisivo en la reducción de la competitividad. Un gran reto para el sector es aumentar la productividad interna, reducir los costos e invertir en tecnologías que mejoran la calidad de los productos.

Palabras clave: Sector del calzado. Ventaja comparativa revelada. Medidas no arancelarias. Informes técnicos. 


\section{Notas}

6.402: Calçados com sola exterior e parte superior em borracha ou plástico.

2 6.403: Calçados com sola exterior de borracha, plástico, couro natural ou reconstituído e parte superior em couro natural.

3 6.406: Partes de calçados (incluídas as partes superiores, mesmo fixadas a solas que não sejam as solas exteriores); palmilhas não removíveis, reforços interiores e artefatos semelhantes e polainas.

\section{Referências}

ABICALÇADOS. A Abicalçados. 2010. Disponível em: <http://www.abicalcados.com.br/site/abicalcados.php?id=5>. Acesso em: ago. 2013.

ANDERSON, P. Barreiras não tarifárias às exportações brasileiras no Mercosul: o caso de calçados. Brasília, DF: Ipea, maio 2001. 21 p. Texto para discussão $\mathrm{n}^{\circ} 791$.

ANDRADE, R. L. P. As consequências positivas das barreiras não tarifárias. In: SILVA, Orlando Monteiro da. Notificações aos acordos de barreiras técnicas (TBT) e sanitárias (SPS) da OMC: transparência comercial ou barreiras não tarifárias? Viçosa, MG: DEE/UFV, 2010. p. 195.

BALASSA, B. Trade liberalization and "reveled" comparative advantage. The Manchester School of Economic and Social Studies. Manchester, v. 33, n. 2, p. 99-123, 1965.

BERTO, A. R. Barreiras ao comércio internacional. In: CONVIBRA - CONGRESSO VIRTUAL BRASILEIRO DE ADMINISTRAÇÃO, 2004, 14 p. Disponível em: <http://www.convibra.com. br/2004/pdf/65.pdf>. Acesso em: 6 nov. 2013.

BRASIL. Ministério das Relações Exteriores. Divisão de Informação Comercial. Como Exportar: Canadá. Brasília: MRE, 2006. 152 p.; (Coleção Estudos e documentos de comércio exterior).

. Ministério das Relações Exteriores. Divisão de Informação Comercial. Como exportar: Dinamarca. Brasília: MRE, 2009. 112 p.; (Coleção Estudos e documentos de comércio exterior).

. Ministério das Relações Exteriores. Divisão de Informação Comercial. Como exportar: Estados Unidos da América. Brasília: O Ministério, 2012. 208 p.; (Coleção Estudos e documentos de comércio exterior).

COSTA, A. B. da. Competitividade da indústria de calçados. Campinas, SP: Consórcio Unicamp-UFRJ-Funcex, 1993. Nota técnica setorial da indústria têxtil.

DECOMTEC. “Custo Brasil” e taxa de câmbio na competitividade da indústria de transformação brasileira. São Paulo: FIESP, 2013. Disponível em: <http://www.fiesp.com.br/indices-pesquisas-e-publicacoes/custo-brasil-na-industria-detransformacao-em-2012-2/>. Acesso em: nov. 2013.

GOMES, W. L. O mercado de produtos lácteos no Mercosul: produção e mercado externo. Viçosa, MG: DEE/UFV, 2013.

GUIMARÃES, V. Para saber mais: a história da indústria calçadista no Brasil. 2010. Disponível em: <http://scorpiurs.com.br/paginas/pagina/historia>. Acesso em: 26 ago. 2013.

KRUGMAN, P.; OBSTFELD, M. Economia Internacional: teoria e política. 8. ed. São Paulo: Pearson Prentice Hall, 2010. 
BARREIRAS COMERCIAIS. Disponível em: <http://www.mdic.gov.br/sistemas_web/aprendex/ default/index/conteudo/id/28>. Acesso em: 5 nov. 2013.

NINIO, M. Custo tira calçadistas brasileiros da China. Folha de São Paulo, 8 de dezembro de 2013, Caderno Mercado, p. B10.

OLIVEIRA, E. Aumento de fluxo comercial entre Brasil e Argentina traz à tona divergências entre países. $O$ Globo, Rio de Janeiro, 30 maio 2007. Disponível em: <http://oglobo.globo.com/ economia/aumento-de-fluxo-comercial-entre-brasil-argentina-traz-tona-divergencias-entre-paises-4185706>. Acesso em: 21 nov. 2013.

PIETROBELLI, A. Argentina barra calçados brasileiros. Monitor mercantil, 18 nov. 2013. Disponível em: <http://www.monitormercantil.com.br/index.php?pagina=Noticias\&Noticia=144439 \&Categoria=NEGOCIOS $>$. Acesso em: 21 nov. 2013.

SISTEMA FIRJAN. Nota técnica, n. 6, nov. 2013. Disponível em: <http://firjan.org.br>. Acesso em: nov. 2013.

UNITED STATES INTERNATIONAL TRADE COMMISSION. Harmonized tariff schedule of the United States: Annotated for Statistical Reporting Purposes. Washington, D.C: U.S. Government Printing Office, 2014. Disponivel em: <http://www.usitc.gov/publications/docs/tata/hts/ bychapter/1400htsa.pdf>. Acesso em: 21 nov. 2013.

WORLD BANK. World Integrated Trade Solution (WITS). Disponível em: <http://wits.worldbank.org>. Acesso em: set. 2013.

WORLD TRADE ORGANIZATION (WTO). Database. Disponível em: <https://www.wto.org>. Acesso em: set. 2013. 


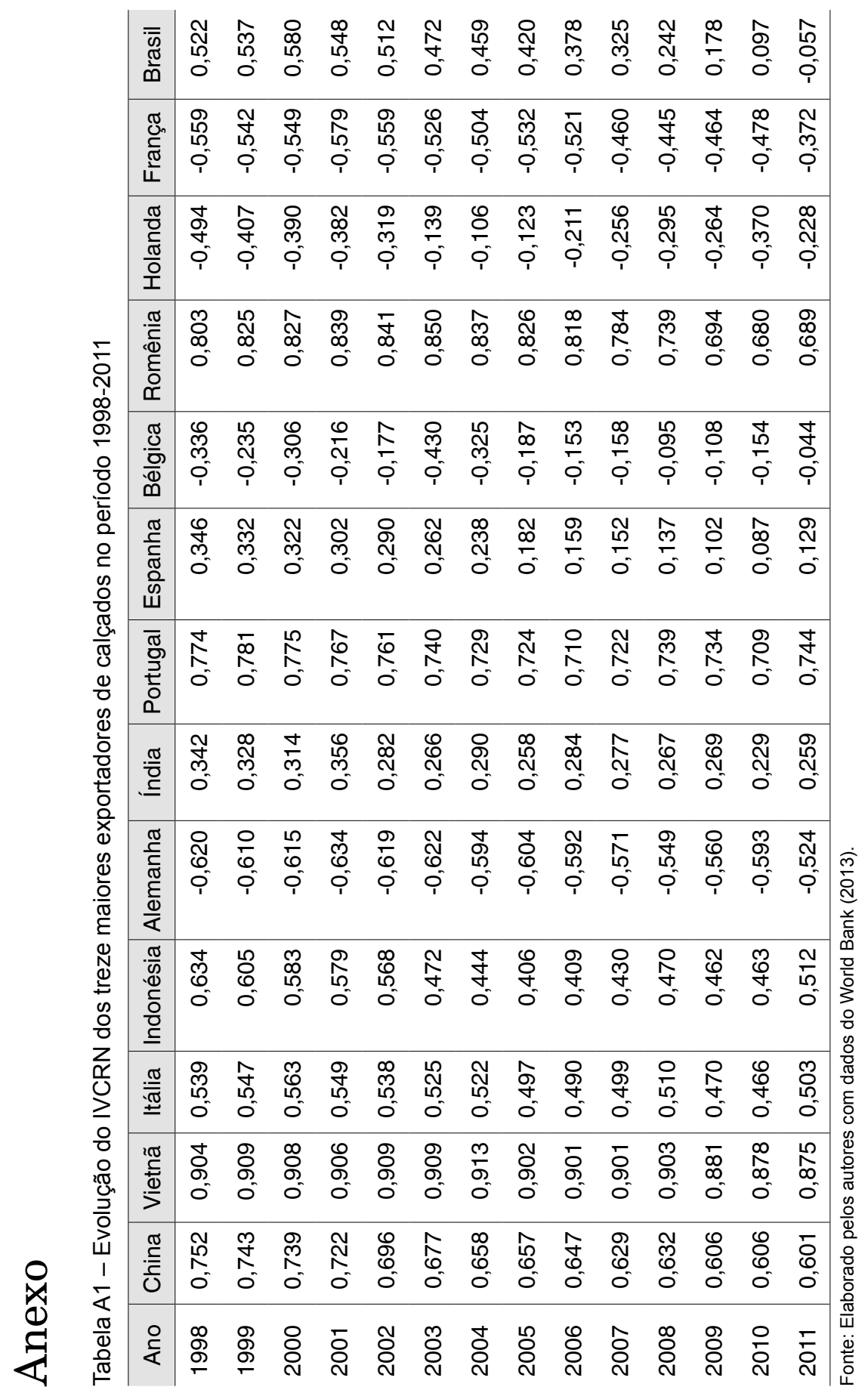

